Relations industrielles

Industrial Relations

\title{
Les relations du travail, employeurs, personnel, syndicats, État, par Dimitri Weiss, Paris, Série " gestion sociale ", Éditions Dunod, 1974, 160 pp.
}

\section{Félix Quinet}

Volume 29, numéro 3, 1974

URI : https://id.erudit.org/iderudit/028539ar

DOI : https://doi.org/10.7202/028539ar

Aller au sommaire du numéro

\section{Éditeur(s)}

Département des relations industrielles de l'Université Laval

\section{ISSN}

0034-379X (imprimé)

1703-8138 (numérique)

Découvrir la revue

Citer ce compte rendu

Quinet, F. (1974). Compte rendu de [Les relations du travail, employeurs, personnel, syndicats, État, par Dimitri Weiss, Paris, Série " gestion sociale ", Éditions Dunod, 1974, 160 pp.] Relations industrielles / Industrial Relations, 29(3), 622-622. https://doi.org/10.7202/028539ar

Tous droits réservés @ Département des relations industrielles de l'Université Laval, 1974
Ce document est protégé par la loi sur le droit d'auteur. L’utilisation des services d’Érudit (y compris la reproduction) est assujettie à sa politique d'utilisation que vous pouvez consulter en ligne.

https://apropos.erudit.org/fr/usagers/politique-dutilisation/ 
qu'autant ils n'ont pas de scrupules à se plier à des ordres venant de Moscou autant ils sont opposés à toute influence venant des Etats-Unis. La direction du CTC est amenée à lutter sur deux fronts.

On y constate le rôle important qu'ont joué certains personnages comme Charles Millard et surtout Pat Conroy. D'une manière générale, les individus dans leurs luttes pour le pouvoir ou pour le triomphe de leur façon de voir le syndicalisme, son rôle, son action et ses rapports avec les partis politiques apparaissent sous une lumière bien différente de celle que l'on trouve soit dans les journaux ou la propagande syndicale. En dévoilant les côtés mesquins qui se mêlent à l'action quotidienne et aux stratégies utilisées, l'auteur, dans son rôle d'observateur impartial effectue un travail de démystification sans pour cela diminuer les hommes ou le mouvement syndical.

On pourra ne pas être d'accord avec l'auteur dans toutes ses conclusions particulièrement sur le rôle positif qu'auraient joué les leaders communistes si on ne les avait pas délogés et sur son pessimisme vis-à-vis de la canadianisation des syndicats. Son ouvrage est toutefois une des contributions les plus valables à l'histoire du syndicalisme au Canada.

\section{Université Laval}

Les relations du travail, employeurs, personnel, syndicats, Etat, par Dimitri Weiss, Paris, Série "gestion sociale 》, Editions Dunod, 1974, 160 pp.

Ce nouveau livre que Dimitri Weiss consacre aux relations industrielles est plus que le précédent (que nous avions eu le plaisir de recenser dans Relations Industrielles, vol. 28, no 3) axé sur le système français des relations du travail. Par ailleurs, il comporte, comme l'ouvrage précédent, un très utile souci de clarification sur le plan des conceptsclés. Pour ne citer qu'un exemple, nous avons trouvé fort utiles les définitions et explications que l'auteur fournit au sujet des différents types de conflits du travail : de telles mises-en-ordre ne peuvent que faciliter l'identification des problèmes, puis leur discussion ordonnée, deux choses qui, en relations industrielles, sont éminemment utiles. Nous ne croyons pas nous aventurer trop loin en disant que pour le lecteur nord-américain, le chapitre de l'ouvrage qui traite de \& La Négociation Collective» (Chapitre 3) et celui qui traite des «.... Institutions de représentation du personnel dans l'entreprise » (Chapitre 4) revêtiront un intérêt particulier. D'une façon plus précise, on ne peut être, de ce côté-ci de l'Atlantique, qu'intéressé par l'examen et la discussion de questions et développements résultant de la coexistence, au sein d'entreprises françaises, du Comité d'Entreprise et de la Section Syndicale. Et même s'il est trop loin pour prendre position, le lecteur d'ici ne manquera pas de relever avec intérêt, au sujet de la convention d'entreprise, les commentaires qui sont offerts et cités dans l'ouvrage (voir le sous-chapitre intitulé «les conventions d'entreprise ou d'établissement » pp. 58-61). Pour ceux qui, parfois, sont friands de rapprochements, l'ouvrage contient aussi des citations qui ne manqueront pas, même à distance, de faire réfléchir. Par exemple, après avoir évoqué le «syndicalisme d'entreprise», on propose une distinction entre le syndicalisme d'entreprise » à l'américaine » et la "présence syndicale dans l'entreprise ", cette dernière expression étant présentée comme collant peut-être plus à la réalité française (p. 71). En laissant évidemment à l'auteur la responsabilité de ses orientations et de ses choix, l'on ne peut que conseiller la lecture de ce livre, clairement et vivement écrit. En plus de leur valeur incontestablement éducative, des ouvrages tels que celui-ci et traitant du système de relations de travail d'autres pays, nous aident à mieux situer, et à mieux comprendre les particularités de notre propre système.

Félix QUINET

Commission des relations de travail dans la fonction publique,

Ottawa

Managerial Motivation and Compensation, by H. L. Tosi, R. J. House and M. D. Dunnette, (ed.), A Selection of Readings, East Lansing, Michigan, MSU Business Studies, 1972, 539 p.

Présenter une série d'articles traitant de la motivation et de la rétribution, articles d'intérêt à la fois pour les administrateurs et les théoriciens du Management, tel était l'objectif des éditeurs de 